\title{
Academic Mobility in an Emerging European Research Area: Perception and Realization of its Instruments among PhD Candidates
}

This paper considers perception and realization of EU-offered instruments and frameworks from the perspective of intra-EU mobile PhD candidates. In the context of current discussions about European Union research policies and their development, this paper shows who, how and under what circumstances doctoral candidates are participating and evaluating programs designed to encourage mobility and 'excellence'. The basis for this research is 38 interviews with mobile PhDs candidates. It is shown that general knowledge about these programs is limited but positive, as the programs are known for their prestige. Universities and colleagues are the main distributors of information. The majority of our sample are not taking part in such programs and have no concrete plans to do so. This may be connected to their status as early-career scientists and their uncertain future. mobility

Keywords: European Union; European Research Area; doctoral candidates; academic

\section{Introduction}

The European Union and its programs in higher education promote migration and free movement within the borders of the EU for scientists. This is an attempt to build and strengthen European identity among researchers from different EU countries and to realize the 'European Research Area' (ERA) as a coherent and united

${ }^{1}$ Contact: Gregor Schäfer, gregor.schaefer@uni-siegen.de 
supranational job market. Such EU programs are based in the current framework program of Horizon 2020. They aim to make intra-EU movements and work for individuals more practical. Europeanization as a general process (Altbach 2015) as well as specific programs and funding from the European Union (Enders 2004; Baier \& Massih-Tehrani 2016), such as Marie Skłodowska-Curie Actions (MSCA), are much discussed topics in the field of higher education research. However, most of the research is done from a macro-institutional perspective and deals with efficiency and effectiveness of those programs and framework in quantitative terms (e.g., Chou 2014; Repeckaite 2016). The same applies to the various evaluations of the European Commission (EC) about their policies (e.g., European Commission 2012, 2014a).

This paper takes a different perspective. The two main research questions are: What relevance do the EU framework and its programs have for mobile $\mathrm{PhD}$ candidates? What orientation can be found amongst the mobile researchers who use the programs and those who do not use them? Examples of specific EU programs are Marie Skłodowska-Curie Actions (MSCA) and EURAXESS. These will be used for this paper, because they are available for $\mathrm{PhD}$ candidates in contrast to other EU programs, which are only open to postdocs and senior researchers. Individual perspectives and experience are compared with the official outline of the EU. The aims and goals of ERA, Horizon 2020, MSCA and EURAXESS are drawn from statements and strategy papers (European Commission 2014a; European Commission 2016) and previous research.

\section{Background}

The paper considers strategies and efforts from the EU to build a European framework in academia along with perception and usage among scholars. The general trend towards more inter/-transnational mobility amongst researchers is meant to enhance competition between institutions and individuals for the best and brightest ideas, innovations, persons and results, and to overcome local and national scientific traditions that are deemed inefficient (Baier \& Massih-Tehrani 2016). The higher the pressure for mobility in one's research career is, and the more usual it is perceived to be, the more likely a national academic system will open itself up and make structural and institutional changes (ibid.). This is especially true for countries in the European Union, because the EU is actively working towards the European Research Area, and the above-mentioned ideas about competition play a crucial part in its plan. Although Europe was already a big player in the global scientific world before ERA and its countries cooperated more than on other continents (Chou \& Gornitzka 2014), the pressure of competition and EU's losing ground to other parts of the world resulted in the idea of an ERA, to stop 
the development of decreasing share and prestige (van der Hijden 2009). Therefore, the ERA will be examined more in detail.

When the Bologna reform was introduced, the European Commission (EC) was very surprised by it, because it was 'what the Commission had always wanted but was never allowed to do because education was deemed to be a national responsibility' (Kehm 2006: 57). However, the EC immediately began to support the Bologna Process and expanded it to include research and development through the Treaty of Lisbon, to create a common European space and market for higher education and research (ibid.). The enhancement of knowledge exchange through the mobility of academic personnel and students in the context of the ERA was even added as the fifth freedom to the principles of the European Union (Chou 2014). The document, 'Towards a European Research Area' (Commission of the European Communities 2000) embraced specifically the idea that mobility is of high importance for academic development and excellence in the future and should therefore be promoted wherever possible. The member states were asked to remove obstacles to mobility, to foster the circulation of knowledge and improve the quality of education EU-wide (Ackers 2005). 'In addition to its emphasis on mobility and the institutional integration of researchers, the code focuses on improving approaches to the recruitment, selection and evaluation of researchers, encouraging greater transparency, openness and equality in recruitment and selection. Non-discrimination on grounds of nationality (at least among European citizens) is a fundamental principle of European law and one which the Charter upholds in the context of scientific careers.' (ibid.: 307).

Mobility plays an important role in the shaping of the ERA and it is designed to enhance and encourage such academic mobility (European Commission 2001; Morano-Foadi 2005). Later, the issues of social security, pension, employment rights and soft skill training for better employability among mobile researchers were addressed by a new initiative (Ivancheva \& Gourova 2011). The mobility claim was integrated in the '2020 vision' of the EU, which means that 'by 2020, all actors fully benefit from the fifth freedom across the ERA: free circulation of researchers, knowledge and technology' (Ackers 2005: 28). The new model is envisaged as a free trade zone for knowledge and science. 'Horizon 2020, the EU Framework Programme for Research and Innovation (2014-2020), is a key EU asset to this end. It aims to stimulate economic growth and create jobs by coupling $\mathrm{R} \& \mathrm{I}^{2}$, promoting excellent science and industrial leadership, and tackling societal challenges' (European Commission 2018). The implementation of Horizon 2020 is presented as a crucial part of the realization of the ERA (Official Journal of the European Union 2010). In line with the argumentation for the ERA, Horizon 2020 was designed to raise competitiveness and visibility of the $\mathrm{EU}$ as a player in international academic

\footnotetext{
${ }^{2}$ Research and Innovation
} 
competition (Young 2015). Since 1984, when the first framework program (FP1) was introduced, Horizon 2020, the eighth FP, is the first to have a distinctive name. This is to represent its importance and innovation: 'We want the CSF [Common Strategic Framework] to mark a clear departure from business as usual. We are not simply moving from the 7th to the 8th Framework Programme. And what better way to demonstrate this shift than with a new name?' (Geoghegan-Quinn 2011, cited in Young 2015: 17). The budget was extended to $€ 80$ billion, which is significantly higher than previous programs. It also combines top-down and bottom-up approaches for the first time, which is supposed to steer agenda as well as innovation (Kalisz \& Aluchna 2012). It was specifically defined that the new framework should be more than just a mere funding scheme, and that it should coordinate national efforts for better science and also attract more investments from third parties (Young 2015). However, the definition of what is 'better', 'high quality' or 'best science' must be based upon a specific concept. In the case of Horizon 2020, it follows the general outline of the European Commission, which pairs best science with the best research proposals in a competitive environment (European Commission 2013). The same notion of 'best' with the same implications is also used to describe aims and goals for researchers, ideas and infrastructure. Still, it remains unclear how the best proposals can ensure and forecast the best science. And even if they could, there is still the problem of the Matthew-Effect ${ }^{3}$ (Merton 1968). As resources are limited for deciding for or against an application, there is the possibility that decisions also rest upon former reputation, names, etc. and not solely on the quality, innovation and the like of the proposal. There is also the matter of whether funding 'excellence research' should be distributed between European countries more or less equally, or concentrated in few but very prestigious and internationally visible places. The mobility of researchers is an important factor here; they could either stay in their home country or region, to benefit from funding for smaller universities and research institutions, or move to centers of visibility (Young 2015). Another important point for the scholars is bureaucracy and paperwork when applying for funding from the framework program. Horizon 2020 aims to simplify and harmonize the application process to cut back time and effort expended on filling in forms (Horvat 2011).

Marie Skłodowska-Curie Actions, named after the first female Nobel Prize winner, is part of the 7th Framework Program, which aims to promote research and innovation in universities and other research institutions. Marie Curie Actions consist of various parts and schemes that all share one feature: the requirement of European mobility. Applicants must be citizen of an EU member state, and cooperation with and movement to other European scientific institutions is compulsory

${ }^{3}$ The Matthew-Effect borrows its name from the biblical gospel of Matthew: those who have will get more, while those who have less or nothing will lose even more. 
(Ackers 2005). In many cases, this includes at least three different countries. One part of the Actions is Initial Training Networks (ITN), which focuses on 'doctoral education and aimed to improve career prospects for doctoral candidates, called early career researchers, by offering them mobility, access to high-quality research infrastructures, and competitive funding. ITN accounted for around 40 percent of the budget of Marie Curie Actions' (Repeckaite 2016: 258). It is accessible in two forms. The first is host funding, where the research institution applies for the money and creates open positions for researchers, which will then be advertised. This form is most common amongst doctoral candidates, as it was also the case in our sample. The alternative is individual funding, where the researcher, most likely a postdoc, applies directly for financial support for a research project at the Commission (Ackers 2005). Within the framework of MSCA (and in Horizon 2020 in general), $\mathrm{PhD}$ candidates are defined as junior researchers, and not primarily as students, which puts them in the sphere of the ERA and not of the EHEA.

EURAXESS is an internet portal that lists science jobs. Target groups are employers, such as university, research institutes and the research facilities of private companies and employees in the fields of research and development. It lists every position within the European Union, regardless of the field of science or career stage (European Commission 2009). The European Commission itself admits that the visibility could be better amongst the scientific community. Only nine percent know of it and only seven percent have used it in the past. This stands in stark contrast to other sources of information, like acquaintances, colleagues or institutions, which 60 percent of academics surveyed have used (ibid.). The goal of EURAXESS is to foster an 'open, transparent and merit-based recruitment' (Deloitte 2014: 46) and to function as an indicator on the openness of national recruitment systems. This is seen as 'indispensable for the realisation of ERA' (ibid.: 46).

The frameworks and programs are sometimes criticized as contributors to social stratification in the academic sphere, as they can spark the Matthew-Effect. Applied to this context, it means that instruments and funding from the EU will primarily benefit those who already have been more mobile than the average before, which is often connected to their social background (Netz \& Jaksztat 2014). This deepens social differences, as a program like MSCA will boost scientific careers even more. Another criticism is raised in connection with the EU-proclaimed concept of 'brain circulation' (Musselin 2004) in a program like MSCA. As previous studies (Ackers 2005; Münch 2016) showed, countries and centers of academic reputation drain scholars from countries with limitations, which include low salaries, poorer quality of research and education, limited access to scientific infrastructure, and poorer quality of life (Fernández-Zubieta \& Guy 2010). If remigration afterwards is not the usual pattern and the rate of incoming and outgoing scholars is imbalanced, there is a brain drain instead of brain circulation. This was observed with MSCA fellows in the year 2000 (ibid.). Countries with a good academic reputation, like 
the UK, the Netherlands, Switzerland, Austria and the Scandinavian countries, hosted more foreign fellows when their own nationals went abroad with the help of MSCA. The opposite occurred in countries with less prestige, like Spain, Italy, Greece and Poland.

\section{Methods and fieldwork}

The data collection and this paper are part of the project 'Mobile transitions mobile lifestyles? Career choices and way of living at the transition to transnational scientific careers in the European Union' at the University of Siegen (Schittenhelm, El Dali \& Schäfer 2017). Empirical data are collected through biographical interviews from graduates of the SSH (social sciences and humanities), who completed their studies at German universities and were working as $\mathrm{PhD}$ candidates at Dutch or French universities at the time of the interviews. Mobility in the SSH is less frequent and harder to achieve (Ackers 2008; Ackers 2013), because 'language skills and cultural knowledge are often necessary for conducting research projects' (Jöns 2007: 88). The sample was therefore limited to these fields of science to achieve a better comparison. France and the Netherlands have the highest percentage of Germans amongst students and academic staff in the EU after the UK and Germanspeaking countries. The research is still ongoing and 45 interviews have been conducted since December 2016. Graduate schools and individual researchers were contacted via e-mail with our request for interview partners. Contact addresses have been found on the websites of the universities, faculties and graduate schools as well as with the help of personal third-party contacts. The administrators at graduate schools functioned as gatekeepers to potential interviewees, and distributed our request via mailing lists. Another way of finding interview candidates was the browsing of the staff member lists of the universities. Employees with (supposedly) German names were contacted by us directly. This approach has the disadvantage of only including ethnic Germans, while it cannot find Germans with migration background or foreigners who studied in Germany. However, because this was not our exclusive approach to find candidates, our sample also includes the latter groups, which were found through graduate schools and personal contacts. In a later adjustment due to the low response rate, we also included people who either only did one degree (e.g., bachelor's) in Germany, or went to school in Germany, or had already completed their $\mathrm{PhD}$ up to three years before the time of the interview. The biographical interview format was used throughout the project and can be specifically utilized for this research question as an explorative instrument. It gives the interviewees the chance to emphasize relevant topics without imposing the researcher's ideas and notions on them (Corbin \& Morse 2003). We started with open stimulus, to put interviewees at ease and allow them to speak 
freely. This ensures a good quality of information, because the interviewee is not forced to talk about a certain topic. Rather they cover subjects that are important to them, which should enhance motivation and contribute to the quality of responses (Juhasz Liebermann 2012). An interview guideline was only used for topics, that were not addresses by the interviewees themselves. For analysis, a combination of Documentary Method (Bohnsack 2014) and Grounded Theory (Glaser \& Strauss 1967; Strauss \& Corbin 1990) was applied. The former is especially fruitful in combination with the explorative function of the interview design. It uncovers orientation and perspectives on EU frameworks and programs. The latter one is useful for organizing the analysis over the large number of interviews. The findings of the interviews are compared with the official presentation and requirements of the EU frameworks and program as described above. In particular, the need and expectation for mobility will be put in contrast. All but one interview was conducted in German. The analysis is based on the original German transcripts, and quotations from interviewees in this paper are translated by the author, except for the one interview in English (Carla). Names of people and locations have been altered.

After compiling outline of general research interests, I looked specifically into sections of the interview that dealt with EU-related experiences. These sections were coded and categorized for further analysis with Reflective Interpretation as part of the Documentary Method (Nohl 2013).

\section{Results}

As a consequence of the analysis, I elaborated on three groups for the perception of the EU framework and its instruments: a) personal involvement, b) little knowledge and further interest, c) peripheral knowledge and no further interest. These groups were differentiated through their approach to addressing the topic, their factual knowledge and self-proclaimed interest in it. Each group is represented by selected excerpts from the sample. This does not imply that these groups are completely distinguishable from each other. Certainly, their borders are fluid and the group titles only represent ideal types of knowledge and usage, whereas a concrete case can often be located only somewhere in between. EURAXESS as an example for an $\mathrm{EU}$ program of relevance for $\mathrm{PhD}$ candidates will not be further discussed, as there was only one participant (Marlis) who actually used it and another one who 'thinks he has heard of it' (David: 2954) but never used it for himself. No other respondents knew anything about it. This may not surprise, as the earlier-mentioned statistics about ERAXESS showed (European Commission 2009). Results from another survey confirm the very low visibility of the portal (Gourova \& Sanopoulos 2010).

\footnotetext{
${ }^{4}$ Numbers behind interviewee's names or interview quotes indicate lines in the transcript.
} 


\section{Personal involvement}

For the Documentary Method, it is not just what is said that is important, but more how it is said. The main differentiation between this group and the other three is the mentioning of an EU program (MSCA in this case) without being asked about it by the interviewer. Not surprisingly, those researchers whose position had been financed through the MSCA, fall into this group. When they talked about their positions and funding, they also mentioned the source of funding. In contrast, it was not mentioned by other interviewees who were paid by their university when they talked about salary and position. People who were funded by national grants (especially the Organisatie voor Wetenschappelijk Onderzoek (NWO)) put more emphasis on the source of income. The more exotic or exclusive the source of income was, the more likely the interviewees were to mention it. There was another case where the person's $\mathrm{PhD}$ position had been financed by the European Research Council (ERC). To elaborate my point, I will draw on those cases that were financed by the MSCA, because they were the only ones to emphasize the topic themselves, which indicated high importance.

When the beneficiaries of MSCA started to talk about it, they began with the financial aspect and mobility respectively. For Carla, the higher salary compared to other PhDs at her faculty, was seen as a helpful advantage. This was because she needed to settle in a new environment where she had to buy new things and 'spend a fortune here buying everything' (606). This points to an earmarked use of her income, which is seen primarily as an enabler for her mobility and not as extra disposable income for private activities or shopping. Martin mentioned salary later in his response, where he downplayed the difference between his salary and those from other members of his department. He mentioned that he only gets a higher salary for the first year of his $\mathrm{PhD}$, which will be equalized in following years. Regardless of objective truth, this shows that he tried to avoid distinction through economic capital. Instead, distinction is created though symbolic capital (Bourdieu 1983). His supervisors were 'very proud' (626) of the creation of the MSCA PhD position, because 'funding from the European Commission is a great figurehead' (627) and it is very 'prestigious in the Social Sciences' (628) and they were 'happy to create the position' (630). In this passage, it remained unclear whether his supervisors were proud of him or themselves. Without doubt, their pride was connected to MSCA funding, which was the source of the position's symbolic force. Symbolic power is created through the scarcity of opportunities for funding from the EU. The success rates are between 14 and 15 percent for MSCA (Myklebust 2015). Carla also stressed the symbolic meaning of her MSCA position, but she was not aware of it when she applied for the job. She only found out after she started to work, when 'everyone at the university told me, "Oh! You have a Marie Curie? This is very good" and I say, "Why? I didn't even know about these things" (681). The symbolic 
meaning of her $\mathrm{PhD}$ position only became apparent to her through compliments from colleagues. This shows that information and perception about EU programs is still unequally distributed even amongst the recipients. The symbolic power of EU instruments is closely connected to the mobility they enable (Munk 2009), which itself is a distinction in the academic world (Jaksztat et al. 2011). Mobility was also the first aspect Martin stressed in his narration about MSCA. He only went to the Netherlands, because the application could not be started in Denmark, where he had lived for over two years in total before for his master's and an Erasmus exchange in during his bachelor's degree. Due to a regulation that only allows stays of not more than one year in the last three years in the country of application for MSCA, he had to move to another country if he wanted to apply for funding. However, the initial information about the possibility of an MSCA-financed $\mathrm{PhD}$ came from a workshop at the university where he was doing his master's degree, where there also MSCA-funded positions. This regulation, called 'European Mobility', demands intra-European mobility and Europeanization of the receiving scholar.

Symbolic power attributed to (high) academic mobility is an advantage. But there are also disadvantages connected to mobility. Martin carried on explaining that he chose the MSCA position because of the chance to move around, which was very appealing to him. At the time of his decision he was doing a bachelor's degree. After he found a local girlfriend in the Dutch city of his $\mathrm{PhD}$, his opinion about the mobility expectations and commitments changed a lot. He describes his current life in the Dutch city as 'very pleasant/good' (777) as he 'likes it' (777). Therefore, he has 'absolutely no desire' (776) for the upcoming constant mobility, as he is expected to attend seminars and workshop at partner institutions and is also expected to stay and work there for a period of time. His reluctance is emphasized, as he repeated the phrase 'absolutely no desire' (779). Although he was fully aware of the mobility expectations before he applied for the position, it shows how changes in the private life of academics alter their stance towards the demands of their profession and its institutions (Ackers 2008). Furthermore, in a different passage, he differentiated between the shallow perception of academic mobility from the outside, where it seems interesting and 'better than it is' but 'it is not as great as it sounds. [...] You arrive in Madrid in the evening, tired, and you just want to sleep, the bed in the hostel is uncomfortable. And of course, you don't tell something like this. In that sense, mobility sounds more attractive to others than it is for yourself.' (1296). Negative aspects of mobility are seldom addresses by the EU documents. If they are, they focus on professional aspects, such as 'progression in their remuneration' or declining job options (European Commission 2014b: 25). The negative impacts of mobility on private life are not considered or discussed. Scientists are imaged as self-optimized workers, with no strings attached when, in fact, private considerations do matter (Ackers 2005; Cox \& Verbeek 2008; Jaksztat et al. 2011). Nevertheless, the MSCA can also have minor positive side effects for 
the private life of its recipients, as Carla explains. She met another $\mathrm{PhD}$ candidate in the program and befriended her after a while. Although certainly not crucial to the program, these social components can be a very nice addition for the candidates, as most of them moved to a new place for their MSCA position, where they still have to build their social networks. As the salary was not of great importance to her, something different was stressed as helpful and positive:

II think the best thing with this is like there is a lot of money for research [...] could have like people transcribing and even if it's a lot of money, no problem, because it's a lot of money like this, //mhm// a lot of money like that will not be used' (646)

For her, the better conditions in her MSCA position are not primarily reflected by a better salary, but by better financial resources for her research. All spending that is connected to her fieldwork, could be covered with money from the MSCA, which she saw as a greater degree of freedom and ease in her empirical research in comparison to other PhDs. She was very satisfied with these benefits, as she was not even able to spend the whole amount of money available. This was seconded by Martin, who mentioned a 'big budget' (307). The financial status of their positions certainly contributed to the symbolic capital of their work.

In general, both students were bothered less about personal financial gain or improvement, but more about the reputation of their position (Martin) and the research conditions (Carla). Interestingly enough, even they did not have any more or closer information, or interest for that matter, in other EU programs or the general framework of the European Union for academics. It was evident for both cases, that they had to become mobile, in order to start the positions. Both showed a high to very high mobility even before the $\mathrm{PhD}$. They had moved for every cycle of their higher education, firstly between cities, and later between European countries. In that sense, they had accumulated enough 'mobility capital' (Murphy-Lejeune 2003) to be ready and to approve the requirements of mobility for the MSCA. Carla's professional biography was not linear. She worked full-time in different jobs and in different countries between her bachelor's, first master's and second master's degrees. She worked mostly within Europe, but also outside of Europe, in Africa, where she did an exchange for one semester during her second master's. She showed a willingness for high work-related mobility in general, which was not limited to Europe. She was Europe-orientated in terms of academic mobility, because she realized how big the quality differences of research and teaching are outside of the European academic system. Martin's professional biography was much more linear, as he did not work between his bachelor's degree in Germany, master's degree in Denmark, or $\mathrm{PhD}$ in the Netherlands. His narration about future plans involved mostly these three countries, where he had some kind of professional and/or private network. His MSCA position contributed to the establishment of such networks 
and is therefore in line with the outline of the frameworks. Furthermore, both were integrated in structured and internationalized doctoral programs, as was the aim in the ERA. Both realized European mobility within the EU framework before. Martin did an Erasmus program exchange to Denmark. Carla's second master's was an Erasmus Mundus ${ }^{5}$ program, which raises the question of the Matthew Effect (Merton 1968) in the design of EU programs and if they are possibly only preaching to the converted. Carla was already highly mobile beforehand.

\section{Little knowledge and further interest}

The common orientation in this group was a notion of the frameworks and programs, but without specific or detailed knowledge. Interviewees did not talk about the relevant topics themselves but were ask about it by the interviewer. No concrete application attempts had been made so far. They separated themselves from the third group with their further interest in usage of the EU instruments and frameworks. The limited information's they had were received through workshops and information pamphlets at their universities and via senior colleagues who had been successful in gaining EU funding.

'Yes, yes. Those, yes, of course, those are things, which you can read homepage. Errm, what that includes and how to apply for it somehow and if it is an option.' (Samuel: 1946)

The way the information is presented differs from the information itself. By using the non-personal term 'you' instead of 'I', he distances himself from a specific activity that could be related to the interviewer's question if and how he knows about EU programs and frameworks. Following information's are presented vaguely and without specification. Nevertheless, he continued to explain that he wanted to engage himself more in those activities with the goal of establishing an international postdoc project. The wish for more internationalization arose from the discontent with the narrowness and small size of his discipline in the Netherlands, which he described as a 'limited scientific world' (1954). At the same time, he rejected the idea of going back to Germany and being part of a national context and only working with Germans. He 'really would like to see some bridges' (1957) between the two scientific cultures in his field. The difference between the two academic traditions in his discipline played a crucial role in his narration overall. After years of working in Dutch universities, he still struggled with different scientific paradigms. The programs and frameworks mentioned present possible

${ }^{5}$ Erasmus Mundus is a cooperation and mobility program from the EU to enhance the mobility of master's students. The candidate studies their master's at two to three partner universities in different countries. 
opportunities to overcome national inertia and other problems he saw as someone who knew both systems and traditions.

Similar national differences are described by another interviewee (Michael) in a French context. He was more familiar with the relevant programs and had already made an unsuccessful application attempt in cooperation with his wife, who is also a scientist. He acknowledges EU mobility and the involvement with EU programs as a strategic benefit for a scholar's career in general. At the same time, he distanced himself through his wording from a development that he obviously sees just as a current trend in the acquiring of funding:

If I look at this document [official statement from his university] here, how it includes these [EU-related] terms, to have better arguments.' (Michael: 2912)

For his personal career development, he aims to 'enter' (2916) the French system. Therefore, his orientation is primarily 'nationally orientated' (2928), because he sees the French academic system as very national and closed, and that EU programs would not help his cause. Only after he had found his place in the French system would he look out for other frameworks. However, like Samuel, he would like to use EU structures to overcome national barriers in his academic discipline. Similarly, he criticized a big gap and separation in the discourse and tradition between France and Germany in his field of expertise. For the moment, he expressed disappointment with the ERA, as he imagined it as far more developed with fewer obstacles for mobile researchers in daily life but also in cooperation and interplay between the national academic systems. This statement was complemented afterwards with the reservation that this observation might be only true for France. This is a point that is wise to consider, as countries show differences in the implementation of superordinate EU structures (European Commission 2014a). The respondents expanded their scientific interest across national borders, aimed for synergies and were interested in work relations or projects that were more Europe-centered. This is certainly something that can be described as desirable by the frameworks. But they were not blind to problems and barriers related to EU funding. This is an overlap with the third group, as similar obstacles are described such as too much paperwork, low success rates, problems with cross-border coordination, discrepancies between application effort and outcome. Their own efforts towards more and deeper European collaboration can only be as good as the infrastructure allows it to be. It certainly jeopardizes future engagement and motivation if scientists see that the structures and circumstances are insufficient to realize a certain idea or project. Their scientific careers were nationally focused. but because they had the experience of moving and working in a different country, they were more aware of disadvantages or problems in the academic systems of their choices. The usage and perception of EU programs and EU frameworks were less an approach for personal career development, but seen 
as a chance to improve the quality of doing research by fostering intra-European cooperation. The idea was to have a more intense scientific cooperation in Europe than a space where the scientists themselves would move around.

\section{Peripheral knowledge and no further interest}

Most interviewees can be found in this group. They also had some information about EU programs but were, in contrast to the second group, not interested in further usage. As in general, the MSCA was the most prominent instrument.

Marie Curie is a big topic here too and this is also the only gateway, through which I know about Horizon 2020. (Alena: 846)

As they have no personal experience with programs or frameworks and no imminent urge to take advantage of them, their arguments and orientation against a use or interest at the time of their $\mathrm{PhD}$ are presented. When asked for programs and frameworks, they stated that their university put a lot of emphasis on programs from the European Union and encourages the staff to apply for such funding. This engagement included workshops with general information about the opportunities and classes on how to apply for the relevant funding. This is in line with observations from other research: 'We are beginning to see significant investment from universities and other research organizations in administrative functions aimed at increasing the chance of obtaining EU funding' (Young 2015: 28). This engagement can be seen as an appraisal of the symbolic impact these funding initiatives have (see the first group). After all, the university also profits from the fundraising efforts of their academic stuff, as success with funding is a popular indicator for university rankings (Ordorika \& Lloyd 2015). It can also indicate that funding from universities is cut back and scientists have to look out for third-party funding for their research. A development that is not unfamiliar to the general academic world (Enders et al. 2015). This was mentioned by one interviewee in the Netherlands, who was not part of our core sample, because she had graduated from her $\mathrm{PhD}$ several years before the interviews. However, her long-term experience in research showed her that universities had put more pressure on scientists to fund themselves over the decades. This university's activities were described from the perspective of a non-involved observer, who is not encouraged or particularly interested in those activities. Even though the universities presented the EU-programs as a possibility for follow-up financing when the $\mathrm{PhD}$ comes to an end, the interviewees showed little enthusiasm for it. Those in their earlier stages of their $\mathrm{PhD}$ research were not yet bothered about subsequence finance. Academics usually have to deal with uncertainty when it comes to their career planning (Möller 2011; Sigl 2015), which 
means they have to show flexibility and think in the short term. This may give an explanation for why no specific plans for the period after the $\mathrm{PhD}$ were made. After all, they were unsure whether they wanted to stay in science or leave it after their doctoral studies. Work in a MSCA position (or similar programs) was imagined as 'incredible pressure' (Vanessa: 1354) and the application process as something with 'very, very, very many formalities' (Julia: 944). Those motifs were repeated several times. Especially the last point stands in contrast to the guideline of Horizon 2020 to 'continue simplification' (European Commission 2018: 5) in comparison to the predecessor framework FP7.

The perception was rather distant and the efforts of their universities to stimulate fundraising from the EU were mocked as 'hysteria' (Alper: 1462). Surprisingly, the last quote was the viewpoint of the only $\mathrm{PhD}$ candidate who was financed through the ERC. His future planning involved less mobility and a more settled life with his wife, which he deemed incompatible with the demands of EU instruments. The disadvantage of the demand for high mobility that was already described in the first group was also a decisive factor in this group, when another interviewee with children stated that the requirements for intra-European mobility for the MSCA were not an option in her situation. Here again, private circumstances shaped perception of the EU program quite negatively. As we saw in the first group, a relationship complicates the requirement high mobility, but does not make it impossible. Having children or other personal factors that require a person to stay in one place, like care of elderly relatives (Ackers 2005) - rules EU programs out as an option almost entirely. Similar to Martin's negative approach to mobility (first group), the personal situations and circumstances of scholars are not taken into account in the EU programs and frameworks. People of limited mobility are excluded in the first place. Other cases had spatial reference points. These were either the parents or the partner or both, around whom mobility plans evolved. Proximity to these points of reference was an important and decisive factor for mobility, which means they planned their career steps along geographical considerations. They could consider crossing national borders, but only to countries or cities close to their center of reference. In these cases, the demand for high mobility throughout Europe was also unattractive. As all of our interviewees were mobile scholars who went abroad for their $\mathrm{PhD}$, above-average mobility could be detected. Mobility decisions are mostly the result of past mobility and will encourage further mobility (Lörz et al. 2016). Therefore, there was a high degree of mobility in Europe, which resulted in a certain awareness of Europe and the EU, which likely cannot be found amongst domestic doctoral candidates. Some interviewees were mobile beyond Europe and included other world regions in their academic biography for various reasons. There were private reasons, like the origin of a partner and the wish to go back to the home country. There were also mobility considerations for prestige and career development. This was especially true for mobility in the USA. Others planned 
longer research-related stays outside of Europe. For all those cases, programs and frameworks that aim exclusively at intra-European mobility may seem just not relevant enough for an academic future. In the context of USA-orientated interviewees, the EU frameworks seem not to comply with aims to make the EU more attractive and to keep European researchers in Europe.

Another factor acting against further interest was the status of employment within the MSCA when granted for an individual scientist and not for a university or another research institution. In the latter case, the MSCA transforms into paid employment at the funded institution. But individual funding is paid as a scholarship, meaning no insurance, social security etc. These terms were seen as too unattractive for future planning by some of the respondents, which is in line with research (Cox \& Verbeek 2008). Then again, this is a problem faced by many postdocs regardless of EU funding (Weijden et al. 2016). Interviewees who mentioned this problem were more concerned about security in general and preferred secure employment either within or outside the academic system. This shows that applicants for MSCA and the like must deal with a certain degree of risk-taking. Another pattern in this group was the higher relevance of topic-related engagement in a European context in comparison to EU-affiliated frameworks or programs. Examples were memberships and engagements in various European scientific organizations of the respective fields of science. These included the attendance of conferences and summer schools, which represented a chance to meet both old and new European colleagues. These meetings represent a better opportunity for networking, because they allow a relatively small group (as they are topic-focused and specialized) with the same or very similar interests to engage over a longer time on a regular basis. One interviewee describes them as a 'class reunion' (Alper: 1490), which gives a certain degree of intimacy and familiarity. Personal contact represents a central part of recruitment and collaboration for PhDs (Puustinen-Hopper 2005). In this context, EU programs such as MSCA are seen as too anonymous and general to use them for networking or other actions that go beyond financial support. For further financing and employment in sciences, nationally embedded programs and initiatives were stressed as a more interesting option for the future, in contrast to the EU programs. A prominent example is the NWO in the Netherlands, which provides funding for all phases of an academic career. These funding alternatives were presented as more attractive or reachable, as the interviewees were already familiar with the structures and saw them as less competitive. This indication corresponds with previous research on EU frameworks, which are especially popular amongst scientists from countries with weak national funding opportunities (Morano-Foadi 2005). On the other hand, academics in countries with good and numerous funding schemes are less interested or dependent on EU funding.

As the differences between the groups have been presented, the similarities must be addresses as well. All groups shared a common feature when they talked about 
the EU programs and frameworks. It always was discussed primarily as a source of funding. This perspective was articulated by the individual scholars, but it was also perpetuated by universities through workshops on grants and funding. The realization of a common ERA as a more comprehensive concept or vision played no role in the narrations of the interviewees. Nevertheless, as mobile scholars, they benefited from the EU when they moved to another EU country and faced few administrative obstacles. This was certainly stressed as positive by the respondents.

\section{Conclusion}

EU frameworks like ERA and Horizon 2020 and EU programs like the MSCA and ERC are key actions of the EC to forge a European academic space. Besides activities on other institutional levels of science, these initiatives aim to achieve higher mobility among scholars within Europe, and a European job market for academics. This analysis of interviews with doctoral candidates who moved within the European context for their $\mathrm{PhD}$ (and sometimes previous studies cycles) shows that knowledge is mainly limited among these early-stage researchers, but varies with their personal academic involvement and level of engagement. Key concepts and buzzwords of the relevant EU programs and framework were somehow known, but remained irrelevant for most of the early-stage academics. Universities' initiatives to highlight EU funding and make it more visible to the scientists by contributing information about it and helping them to apply for it seem to work, as our interviewees often received their information through their universities. But 'the relative attractiveness of EU funding opportunities (such as the Marie Curie fellowship scheme for example) depends on the opportunities available at national level. In some situations, applications to the Marie Curie scheme, for mobility fellowships reflected not so much a desire for mobility, but rather the sheer lack of opportunities for scientific research in the home country' (Ackers et al. 2001: 9). This also applies to our interview group. Many were financed by national or bi-national research programs and organizations by the time of the interview and saw little relevance or advantage in applying for EU funding in the future. This can be seen as a good situation for national third-party funding in both countries. The minor relevance of the $\mathrm{EU}$ programs for the $\mathrm{PhD}$ candidates can be understood in terms of the very early stage of their scientific career. Many individual funding schemes and programs in the European Union are aimed at scholars at a more advanced stage of their career, such as postdocs and senior researchers (European Commission 2009). The expectation of high mobility in EU programs excludes certain persons, who cannot or do not want to maintain a high level of mobility, such as (young) parents or other private reasons. These mechanisms of exclusion are not based on scientific evaluation and therefore can restrain the academic development of junior researchers with 
potential, who are just 'unlucky' enough to find themselves in situations where the mobility requirement cannot be sufficiently fulfilled. Additionally, EU programs and frameworks are seen as too bureaucratic and the effort to apply for them disproportionately high for an individual application after a $\mathrm{PhD}$, despite other promises for Horizon 2020. Those interviewees who had already benefited from the schemes during their doctoral phase praise their symbolic prestige. Furthermore, the conditions for research are highlighted positively, which eased their work.

Overall, the doctoral candidates did not put much explicit emphasis on EU frameworks and EU programs in their narration. However, their mobility was made implicitly easier by the general legal framework of the EU and a bigger job market. Their mobility, although within the European Union, was more influenced by research topics and personal contacts, which were established outside of the discussed frameworks. It is fair to say that the majority did not follow the guideline of the frameworks and programs discussed. This does not mean that there was no interest or enthusiasm for Europe amongst these interviewees. But the personal realization and mobility did not necessarily develop along the official EU-guidelines. It developed through inter-European friendship, partnership and colleagues. This may not surprise, as a former study showed that 'incorporating an "experience-based" social dimension into the existing theoretical frameworks of political and cultural dimensions of European identity [is needed]. Instead of equating a European identity with an EU identity, such identity should rather be conceived as multilayered. In conclusion, from their experiences abroad and through their social interaction, mobile students from EU states appropriate Europe as a personal project, in which the social predominates over the political' (van Mol 2013: 220). The EU frameworks and programs did not initiate mobility in a top-down way, but can be helpful to realize mobility decisions on the micro level. The presented results have limitations. As a qualitative study, the results cannot be numerically representative. EU programs for students, like Erasmus, were not included, because their visibility is much higher and would demand an article of their own. Also, the questions of personal Europeanization in the context of the ERA was not addressed, as it demands further research. This is also true for the much-discussed brain drain and brain circulation, which could not be discussed in this paper, but play a critical role in the future of the ERA.

\section{References}

Ackers, L. (2005). Moving people and knowledge: Scientific mobility in the European Union. "International Migration", 43(5), 99-131.

Ackers, L. (2005). Promoting scientific mobility and balanced growth in the European research area. "Innovation", 18(3), 301-317.

Ackers, L. (2008). Internationalisation, mobility and metrics: A new form of indirect discrimination? "Minerva", 46(4), 411-435. 
Ackers, L. (2013). Internet mobility, co-presence and purpose: Contextualising internationalisation in research careers. "Sociología y tecnociencia", 3(3), 117.

Ackers, L., Millard, D., Perista, H., Baptista, I., Gustafsson, V., \& Blomqvist, M. (2001). The participation of women researchers in the TMR Marie Curie Fellowships. European CommissionDG Research, Luxembourg: Office for Official Publications of the European Communities.

Altbach, P. (2015). Perspectives on internationalizing higher education. "International Higher Education“. (27).

Baier, C. \& Massih-Tehrani, N. (2016). Europäisierung der Wissenschaft. Auswirkungen der EU-Forschungsförderung auf das universitäre Karrieresystem in Deutschland. In Baur, N., Besio, C., Norkus, M., Petschik, G. (Ed.), Wissen - Organisation - Forschungspraxis. Der Makro-Meso-Mikro-Link in der Wissenschaft.

Bohnsack, R. (2014). Rekonstruktive Sozialforschung. Opladen.

Bourdieu, P. (1983). Ökonomisches Kapital, kulturelles Kapital, soziales Kapital. S. 183-198. Soziale Ungleichheiten. Soziale Welt. Sonderband, 2.

Chou, M-H. (2014). The evolution of the European Research Area as an idea in European integration. In: Chou, M-H., Gornitzka, A. (eds.) Building the Knowledge Economy in Europe: New Constellations in European Research and Higher Education Governance. Cheltenham: Edward Elgar, 27-50.

Chou, M.-H., Gornitzka, A. (2014). Building a Europe of Knowledge: An Introduction to the Dynamics of Policy Domains on the Rise. In: Chou, M.-H., Gornitzka, A. (eds.) Building the Knowledge Economy in Europe: New Constellations in European Research and Higher Education Governance, Cheltenham: Edward Elgar, 1-26.

Commission of the European Communities. (2000). Communication from the Commission to the council, the European parliament, the economic and social committee and the committee of the regions: Towards an European research area. Brussels.

Corbin, J., \& Morse, J. M. (2016). The Unstructured Interactive Interview: Issues of Reciprocity and Risks when Dealing with Sensitive Topics. "Qualitative Inquiry", 9(3), 335-354.

Cox, D., \& Verbeek, A. (2008). Evidence on the main factors inhibiting mobility and career development of researchers. Brussels: European Commission.

Deloitte. (2014). DG Research and Innovation. Researchers' Report 2014. Brussels.

Enders, J. (2004). Research training and careers in transition: A European perspective on the many faces of the Ph. D. "Studies in continuing education", 26(3), 419-429.

Enders, J., Kehm, B. M., \& Schimank, U. (2015). Turning universities into actors on quasi-markets: How new public management reforms affect academic research. In: The changing governance of higher education and research (pp. 89-103). Springer.

European Commission. (2001). A Mobility Strategy for the European Research Area. Brussels. European Commission. (2009). Comparative Survey Analysis on researchers' mobility and career obstacles. Brussels.

European Commission. (2012). Areas of untapped potential for the development of the (ERA): Analysis of the response to the ERA Framework public consultation. Brussels.

European Commission. (2013). Proposal for a Regulation of The European Parliament and of The Council establishing Horizon 2020 - The Framework Programme for Research and Innovation (2014-2020). Brussels.

European Commission. (2014a). European Research Area Progress Report 2014. Brussels. European Commission. (2014b). European Research Area. Facts and Figures 2014. Brussels. European Commission. (2015). Integration of social sciences and humanities in Horizon 2020: Participants, budget and disciplines. Brussels. 
European Commission. (2016). Horizon 2020 Work Programme 2016 - 2017. 3. Marie Skłodowska-Curie Actions. Brussels.

European Commission. (2018). Horizon 2020 interim evaluation: maximising the impact of EU research and innovation. Brussels.

Fernández-Zubieta, A., \& Guy, K. (2010). Developing the European Research Area: Improving knowledge flows via researcher mobility. JRC Scientific and Technical Report, JRC-IPTS.

Geoghegan-Quinn, M. (2011). The future of Social Sciences and Humanities in Horizon 2020. Speech at the British Academy, London, 10.

Glaser, B. \& Strauss, A. (1967). The Discovery of Grounded Theory: Strategies for Qualitative Research. Chicago.

Gourova, E., \& Sanopoulos, D. (2010). Knowledge transfer and mobility: EURAXESS role in Europe. "Diaspora", 7(15), 17.

Horvat, M. (2011). The new framework for EU research and innovation. Science, 334(6059), 1066-1068.

Ivancheva, L., \& Gourova, E. (2011). Challenges for career and mobility of researchers in Europe. "Science and Public Policy", 38(3), 185-198.

Jaksztat, S., Briedis, K., \& Schindler, N. (2011). Die internationale Ausrichtung des wissenschaftlichen Nachwuchses. „HIS:Forum Hochschule”. (10).

Jöns, H. (2007). Transnational mobility and the spaces of knowledge production: A comparison of different academic fields. "Social Geography Discussions", 3(1), 79-119.

Juhasz Liebermann, A. (2012). Biografische Ressourcen-ein zentrales Konzept in der biografischen Bildungs-und Arbeitsmarktforschung. In: Qualitative Bildungs-und Arbeitsmarktforschung. Springer, pp. 241-265.

Kalisz, D.E., \& Aluchna, M. (2012). Research and innovations redefined. Perspectives on European Union initiatives and strategic choices on Horizon 2020. "European Integration Studies" (6), 140-149.

Kehm, B. M. (2006). Doctoral Education in Germany within the European Framework. In: G. Gorzka (Ed.), Europeanising Doctoral Studies: The Russian Federation and Germany on the Way to Bologna. Kassel University Press GmbH.

Lörz, M., Netz, N., \& Quast, H. (2016). Why do students from underprivileged families less often intend to study abroad? "Higher Education", 72(2), 153-174.

Merton, R.K. (1968). The Matthew effect in science: The reward and communication systems of science are considered. "Science", 159(3810), 56-63.

Möller, C. (2015). Herkunft zählt (fast) immer: Soziale Ungleichheiten unter Universitätsprofessorinnen und-professoren: Beltz Juventa.

Morano-Foadi, S. (2005). Scientific mobility, career progression, and excellence in the European research area. "International Migration" 43(5), 133-162.

Münch, R. (2016). Europäisierung des Hochschulraums zwischen globaler Wissensgesellschaft und nationalen Traditionen. Research Brief (2016) TP1.

Munk, M. D. (2009). Transnational investments in informational capital: A comparative study of Denmark, France and Sweden. "Acta Sociologica", 52(1), 5-23.

Murphy-Lejeune, E. (2003). Student mobility and narrative in Europe: The new strangers: Routledge.

Musselin, C. (2004). Towards a European academic labour market? Some lessons drawn from empirical studies on academic mobility. "Higher Education", 48(1), 55-78.

Myklebust, J. P. (2015). Horizon 2020: Surge in applications but low success rate. Retrieved from http://www.universityworldnews.com/article.php?story=20150617162927313 
Netz, N., \& Jaksztat, S. (2014). Mobilised by mobility? Determinants of international mobility plans among doctoral candidates in Germany. In: Academic mobility (pp. 35-59). Emerald Group Publishing Limited.

Nohl, A.-M. (2013). Interview und dokumentarische Methode. Anleitungen für die Forschungspraxis. Wiesbaden.

Official Journal of the European Union. (2010). Consolidated Versions of the Treaty on European Union and of the Treaty on the Functioning of the European Union: Office for Official publications of the European Communities.

Ordorika, I., \& Lloyd, M. (2015). International rankings and the contest for university hegemony. "Journal of Education Policy", 30(3), 385-405.

Puustinen-Hopper, K. (2005). Mobile Minds: Survey of foreign PhD students and researchers in Finland: Academy of Finland Helsinki.

Repečkaite, D. (2016). Reframing European doctoral training for the new ERA. European Journal of Higher Education, 6(3), 256-270.

Schittenhelm, K., El Dali, Y., \& Schäfer, G. (2017). Zwischen Hochschulabschluss und transnationaler Wissenschaftslaufbahn: Berufsausübung und Lebensführung von internationalen Promovierenden. In: A. Neusel \& A. Wolter (Eds.), Mobile Wissenschaft: Internationale Mobilität und Migration in der Hochschule. Frankfurt/New York.

Sigl, L. (2015). Absicherung gibt es überhaupt keine, man kann nur hoffen. „Journal Hochschuldidaktik“, 24.

Strauss, A., \& Corbin, J. (1994). Grounded theory methodology. Handbook of qualitative research, 17, 273-285.

Van der Hijden, P. (2009). European Union initiatives to enhance the attractiveness of the research profession in Europe. "European Educational Research Journal”, 8(4), 550-554.

Van Mol, C. (2013). Intra-European Student Mobility and European Identity: A Successful Marriage? "Population, Space and Place", 19(2), 209-222.

Weijden, I., Teelken, C., Boer, M., \& Drost, M. (2016). Career satisfaction of postdoctoral researchers in relation to their expectations for the future. "Higher Education", 72(1), 25-40.

Young, M. (2015). Shifting policy narratives in Horizon 2020. "Journal of Contemporary European Research", 11(1), p. 16-30. 